\title{
Quantitative determination by HPLC of ent-kaurenoic and grandiflorenic acids in aerial parts of Wedelia paludosa D.C.
}

\author{
R. Batista ${ }^{1,2}$, F.C. Braga ${ }^{2}$, A.B. Oliveira ${ }^{* 2}$ \\ ${ }^{1}$ Departamento de Estudos Básicos e Instrumentais, Universidade Estadual do Sudoeste da Bahia, \\ $B R$ 415, km 03, s/n, 45700-000, Itapetinga, BA, Brazil, \\ ${ }^{2}$ Departamento de Produtos Farmacêuticos, Faculdade de Farmácia, Universidade Federal de \\ Minas Gerais, Av. Antônio Carlos 6627, 31270-901, Belo Horizonte, MG, Brazil
}

\begin{abstract}
There are several reports of biological activity for kaurenoic acid (1), which is found in the aerial parts of Wedelia paludosa D.C., a herbaceous plant of the Asteraceae family abundant in Brazil, and that contains grandiflorenic acid (2) also. Both of these diterpenes were shown to cause lysis of trypomastigotes of the protozoa Trypanosoma cruzi, the causative agent of Chagas' disease (American trypanosomiasis). This paper reports the quantitative determination of these diterpene acids in the aerial parts of $W$. paludosa by an isocratic RP-HPLC method employing $60 \%$ acetonitrile in water and UV detection $(220 \mathrm{~nm})$. Kaurenoic acid (1) was found to be more abundant $(0.85 \pm 0.08 \%)$ while the amount of grandiflorenic acid (2) determined was almost three times lower $(0.32 \pm 0.02 \%)$. No significant seasonal variation was observed for these compounds in $W$. paludosa growing in Belo Horizonte (MG, Brazil) what points out to the aerial parts of this species are a good source of these biologically active diterpenes along all the year.
\end{abstract}

Keywords: Wedelia paludosa, diterpenes, kaurenoic acid, grandiflorenic acid, quantitative determination, RP-HPLC.

\section{INTRODUCTION}

W. paludosa D.C. (Asteraceae) is an herbaceous plant species found in many parts of Brazil, especially in the states of Pernambuco, Bahia, Minas Gerais, São Paulo and Santa Catarina. It is often employed for ornamental purposes and is traditionally used to treat a variety of disorders, including cough and painful conditions (Roque et al., 1987). Several biological effects have been described for W. paludosa extracts including antinociceptive (Block et al., 1998a), trypanosomicidal (Chiari et al., 1996), hypoglycemic (Block et al., 1998b; Novaes et al., 2001), antimicrobial (Vieira et al., 2000) and antifungal (Sartori et al., 2003) activity, among others.

Previous phytochemical studies of W. paludosa afforded ent-kaur-16-en-19-oic acid (kaurenoic acid, 1) and ent-kaur-9(11),16-dien-19-oic acid (grandiflorenic acid, 2) as major compounds, while other kaurane diterpenes, triterpenes and sesquiterpene lactones have been isolated as minor constituents (Carvalho et al., 2001; Batista et al., 1999; Ferreira et al., 1994; Roque et al., 1987).

We have previously reported the in vitro antiTrypanosoma cruzi effect of $W$. paludosa ethanol extract (Chiari et al., 1996). Bioassay-directed fractionation of this extract afforded $\mathbf{1}$ and 2. These diterpenes caused total lysis of trypomastigotes of the protozoa T. cruzi, the causative agent of Chagas disease (American trypanosomiasis), at a concentration of $0.68 \mathrm{mg} / \mathrm{mL}$ (Batista et al., 1999). Several biological effects have been described for kaurenoic acid and related kaurane diterpenoids (Ghisalberti, 1997). Among more recently reported activity for kaurenoic acid should be mentioned the antimicrobial (Zgoda-Pols et al., 2002), anti-platelet aggregation (Yang et al., 2002), analgesic (Block et al., 1998a), antifungal (Sartori et al., 2003), smooth muscle relaxant (Cunha et al., 2003) and hypoglycemic activity (Bresciani et al., 2004). Significant inhibition of HIVreverse transcriptase was exhibited by $16 \alpha, 17$-dihydroxyent-kauran-19-oic acid from Annona glabra (Chang et al., 1998).

The accumulation of kaurenoic acid in some species make these plants important sources of this diterpene that can be used as starting material in the synthesis of new derivatives for biomedical research. Indeed, it has already been submitted to chemical (Vieira et al., 2002; Bruno et al., 2001) and microbial (Silva et al., 1999; Hanson et al., 1995) transformation, affording several derivatives.

Kaurenoic acid (1) is not commercially available, and it is of interest to find easily accessible plant sources for its production. With this purpose, its content has been previously assayed in species of Xylopia (Annonaceae) (Melo et al., 2001), Rabdosia (Lamiaceae) (Kubo et al., 1982) and in Annona glabra (Annonaceae) (Oliveira et al., 2002), by HPLC methods. Furthermore, kaurenoic acid (1) has been determined by GC methods in Asteraceae species, including Mikania glomerata (Vilegas et al., 1997) and Wedelia paludosa (Bresciani et al., 2000; Bresciani et al., 2004). Therefore, the main aim 
of the present work was to develop and validate an HPLC method to quantify both kaurenoic (1) and grandiflorenic (2) acids in aerial parts of $W$. paludosa as well as to evaluate their seasonal variation.

\section{MATERIAL AND METHODS}

\section{NMR data}

${ }^{1} \mathrm{H}$ and ${ }^{13} \mathrm{C}$ NMR spectra were recorded on a Bruker Advance DPX-200 spectrometer $\left({ }^{1} \mathrm{H} 200 \mathrm{MHz}\right.$ and ${ }^{13} \mathrm{C} 50 \mathrm{MHz}$ ) using TMS as internal standard for both nuclei. Samples were dissolved in $\mathrm{CDCl}_{3}$. Chemical shifts $(\delta)$ are given in ppm and $J$ couplings in Hertz $(\mathrm{Hz})$.

\section{Reference substances}

Kaurenoic (1) and grandiflorenic (2) acids were previously isolated from the aerial parts of $W$. paludosa (Batista et al., 1999). The identity and the purity of these diterpenes were checked by HPLC, ${ }^{1} \mathrm{H}$ and ${ }^{13} \mathrm{C}$ NMR analysis.

\section{Plant material}

Samples of aerial parts of $W$. paludosa were collected in Belo Horizonte, Brazil, in January (summer, sample 1), May (autumn, sample 2), August (winter, sample 3) and December (spring, sample 4) 1998, and a voucher specimen is deposited at the UFMG herbarium (BHCB 19033). The plant material was dried at $40^{\circ} \mathrm{C}$ for $72 \mathrm{~h}$, powdered and stored at $-15^{\circ} \mathrm{C}$ until use.

\section{Extraction of the kaurane diterpenes}

An aliquot of the plant material was accurately weighed (400 mg) and extracted only with hexane (30 $\mathrm{mL}$ ) under sonication for $40 \mathrm{~min}$, at room temperature. After removing the hexane in a rotary evaporator $\left(40^{\circ} \mathrm{C}\right)$, the residue was dissolved in $\mathrm{CH}_{3} \mathrm{CN}(2 \mathrm{~mL})$. The solution was filtered on Adsorbex RP-18 cartridges (Merck, Germany), previously conditioned with $\mathrm{CH}_{3} \mathrm{CN}(2 \mathrm{~mL})$, and then centrifuged at $10,000 \mathrm{rpm}$ during $5 \mathrm{~min}$, prior to injection onto the HPLC apparatus.

\section{Chromatographic system}

Analyses were carried out on a Merck-Hitachi apparatus (Germany) composed of a pump L-6200A, automatic injector AS-2000A, UV-VIS detector L4250 and integrator D-2500. An ODS column $(150 \times$ $4.0 \mathrm{~mm}$ I.D., $5 \mu \mathrm{m}$ ) was employed (Merck, Germany) at a temperature of $35^{\circ} \mathrm{C}$, flow rate of $1.0 \mathrm{ml} / \mathrm{min}$ and wavelength of $220 \mathrm{~nm}$. Isocratic elution by $60 \% \mathrm{CH}_{3} \mathrm{CN}$ in water was employed. Solvents used were of HPLC grade (Merck, Darmstadt, Germany) and were degassed by sonication before use. Analyses were performed in triplicate and each sample was injected onto the HPLC apparatus in duplicate.

\section{Calibration graphs}

Five point calibration curves were obtained from $\mathrm{CH}_{3} \mathrm{CN}$ standard solutions of kaurenoic $(1.0 \mathrm{mg} /$ $\mathrm{mL})$ and grandiflorenic $(0.5 \mathrm{mg} / \mathrm{mL})$ acids, injected in the range 5-40 $\mu \mathrm{L}$. The solutions were analyzed and the corresponding peak areas were compared against the mass of the injected kauranes. Each point of the graph was the mean of five measurements. Linear regression equations were obtained by computer analysis, employing Sigma Plot software (Jandell Co., USA). Identification of the diterpenoid peaks in the extracts was made by comparison with the retention time of standard solutions injected in the same conditions.

\section{Recovery studies}

Appropriate amounts of kaurenoic and

Table 1. Recovery of kaurenoic (1) and grandiflorenic (2) acids.

\begin{tabular}{|c|c|c|c|}
\hline \multirow{2}{*}{ Diterpene } & \multirow{2}{*}{ Amount added (mg) } & \multicolumn{2}{|c|}{ Recovery $(n=5)$} \\
\hline & & Mean & R.S.D. \\
\hline \multirow[t]{3}{*}{1} & 3.0 & $101.0 \%$ & 1.9 \\
\hline & 2.2 & $99.5 \%$ & 2.3 \\
\hline & 1.5 & $93.4 \%$ & 4.4 \\
\hline \multirow[t]{3}{*}{2} & 1.2 & $96.6 \%$ & 2.3 \\
\hline & 0.9 & $93.1 \%$ & 2.5 \\
\hline & 0.6 & $83.0 \%$ & 4.6 \\
\hline
\end{tabular}


Table 2. ${ }^{13} \mathrm{C}$ NMR data $(\delta)$ for kaurenoic (1) and grandiflorenic (2) acids.

\begin{tabular}{|c|c|c|c|c|}
\hline \multirow[t]{2}{*}{ Carbon } & \multicolumn{2}{|c|}{ Kaurenoic acid (1) } & \multicolumn{2}{|c|}{ Grandiflorenic acid (2) } \\
\hline & Present work ${ }^{a}$ & Silva et al., $1999^{\mathrm{b}}$ & Present work ${ }^{a}$ & Reynolds, $1984^{\mathrm{a}}$ \\
\hline 1 & 40.7 & 40.7 & 40.7 & 40.7 \\
\hline 2 & 19.1 & 19.1 & 20.1 & 20.1 \\
\hline 3 & 37.7 & 37.7 & 38.2 & 38.2 \\
\hline 4 & 43.2 & 43.2 & 44.7 & 44.7 \\
\hline 5 & 57.1 & 57.0 & 46.6 & 46.6 \\
\hline 6 & 21.8 & 21.8 & 18.4 & 18.4 \\
\hline 7 & 41.3 & 41.3 & 29.6 & 29.7 \\
\hline 8 & 44.2 & 44.2 & 42.2 & 42.3 \\
\hline 9 & 55.1 & 55.1 & 155.9 & 155.9 \\
\hline 10 & 39.7 & 39.7 & 38.8 & 38.8 \\
\hline 11 & 18.4 & 18.4 & 114.9 & 114.9 \\
\hline 12 & 33.1 & 33.1 & 37.9 & 37.9 \\
\hline 13 & 43.8 & 43.8 & 41.2 & 41.2 \\
\hline 14 & 39.7 & 39.7 & 44.9 & 44.9 \\
\hline 15 & 48.9 & 48.9 & 50.3 & 50.3 \\
\hline 16 & 155.9 & 155.8 & 158.5 & 158.5 \\
\hline 17 & 103.0 & 103.0 & 105.5 & 105.5 \\
\hline 18 & 29.0 & 28.9 & 28.2 & 28.2 \\
\hline 19 & 184.8 & 184.9 & 184.7 & 184.7 \\
\hline 20 & 15.6 & 15.6 & 23.6 & 23.6 \\
\hline
\end{tabular}

a $50 \mathrm{MHz}, \mathrm{CDCl}_{3} ; \quad$ b $100 \mathrm{MHz}, \mathrm{CDCl}_{3}$.

grandiflorenic acids were added to plant material, corresponding to 50, 75 and $100 \%$ contents of those acids in the previously assayed material (Table 1 ). The follow-up extractions and HPLC analysis were carried out as described above. The recovery was determined as follows (Chen et al., 2003):

Recovery $(\%)=(A-B) / C \times 100 \%$

where, $A$ is the amount detected, $B$ is the amount of sample without added standards, and $C$ is the amount of the standards added. Recovery studies were performed in 5 replicates for each concentration.

\section{RESULTS AND DISCUSSION}

Kaurenoic (1) and grandiflorenic (2) acids were characterized by ${ }^{1} \mathrm{H}$ and ${ }^{13} \mathrm{C}$ NMR spectra. Characteristic signals were observed for the hydrogens of an exocyclic double bond (1, $\delta 4.73$ and 4.79, $1 \mathrm{H}$ each, s; 2, $\delta 4.79$ 
Table 3. ${ }^{1} \mathrm{H}$ NMR data for kaurenoic (1) and grandiflorenic (2) acids.

\begin{tabular}{|c|c|c|c|c|}
\hline \multirow[t]{2}{*}{ Hydrogen } & \multicolumn{2}{|c|}{ Kaurenoic acid (1) } & \multicolumn{2}{|c|}{ Grandiflorenic acid (2) } \\
\hline & Present work ${ }^{a}$ & Silva et al., $1999^{\mathrm{b}}$ & Present work $^{\mathrm{a}}$ & Reynolds, $1984^{\mathrm{a}, \mathrm{c}}$ \\
\hline 11 & & & $5.24(1 \mathrm{H}, \mathrm{t}, J 3.3)$ & $5.21(1 \mathrm{H})$ \\
\hline 13 & $2.64(1 \mathrm{H}, \mathrm{m})$ & $2.62(1 \mathrm{H}, \mathrm{m})$ & $2.77(1 \mathrm{H}, \mathrm{s})$ & $2.77(1 \mathrm{H})$ \\
\hline $17 \mathrm{a}$ & $4.73(1 \mathrm{H}, \mathrm{s})$ & $4.72(1 \mathrm{H}, \mathrm{s})$ & $4.79(1 \mathrm{H}, \mathrm{s})$ & $4.78(1 \mathrm{H})$ \\
\hline $17 \mathrm{~b}$ & $4.79(1 \mathrm{H}, \mathrm{s})$ & $4.78(1 \mathrm{H}, \mathrm{s})$ & $4.91(1 \mathrm{H}, \mathrm{s})$ & $4.89(1 \mathrm{H})$ \\
\hline 18 & $1.24(3 \mathrm{H}, \mathrm{s})$ & $1.23(3 \mathrm{H}, \mathrm{s})$ & $1.24(3 \mathrm{H})$ & $1.24(3 \mathrm{H})$ \\
\hline 20 & $0.95(3 \mathrm{H}, \mathrm{s})$ & $0.94(3 \mathrm{H}, \mathrm{s})$ & $1.02(3 \mathrm{H})$ & $1.02(3 \mathrm{H})$ \\
\hline
\end{tabular}

a $200 \mathrm{MHz}, \mathrm{CDCl}_{3} ; \quad$ b $400 \mathrm{MHz}, \mathrm{CDCl}_{3} ; \quad$ c Multiplicity not available.

and 4.91, $1 \mathrm{H}$ each, s) and of the methyl groups attached to $\mathrm{C}-4(\mathbf{1}, \delta 1.25, \mathrm{~s}, 3 \mathrm{H} ; \mathbf{2}, \delta 1.23, \mathrm{~s}, 3 \mathrm{H})$ and $\mathrm{C}-10(\mathbf{1}$, $\delta 0.95$, s, 3H; $2, \delta 1.02, \mathrm{~s}, 3 \mathrm{H})$ of the kaurane skeleton. Furthermore, the ${ }^{1} \mathrm{H}$ NMR spectrum of 2 presented a triplet at $\delta 5.24(1 \mathrm{H}, J 3.3 \mathrm{~Hz})$ which was assigned to $\mathrm{H}$ 11. ${ }^{1} \mathrm{H}$ and ${ }^{13} \mathrm{C}$ NMR data for $\mathbf{1}$ and $\mathbf{2}$ (Tables 2 and 3) are in agreement with those previously reported (Reynolds, 1984; Silva et al., 1999).

The quantitative RP-HPLC determination of both kaurenoic (1) and grandiflorenic (2) acids in $W$. paludosa aerial parts is reported here for the first time. The results for repeatability showed relative standard deviations of $1.34 \%$ for 1 and $1.84 \%$ for $2(n=5)$. The results from recovery studies of $\mathbf{1}$ and $\mathbf{2}$ ranged from 83.0 to $101.0 \%$. The relative standard deviations (R.S.D.) of recovery of 1 and 2 ranged between $1.9 \%$ and $4.6 \%$ (Table 1). Good response linearity was obtained for both diterpenes with $r^{2}$ values of 0.9998 (1) and 0.9999 (2) (peak area vs. mass). The linear equations obtained for 1 and 2 were $y=32208.5 x+2432.8$ and $y=108421.3 x+$ 25392.8 respectively. The quantitative limit of the method was established as $1.25 \mu \mathrm{g}$ for $\mathbf{1}(\mathrm{RSD}=2.07 \%)$ and 0.63 $\mu \mathrm{g}$ for $2(\mathrm{RSD}=2.67 \%)$.

A typical chromatogram obtained in the present study is shown in Figure 1. Attempts to improve resolution of kaurenoic acid, including modifications of the strength and selectivity of eluents, were unsuccessful. According to Snyder et al. (1997), resolution $R_{\mathrm{s}}>2.0$ between the peaks of interest is desired for good quantitative determination. While it is feasible to determine two peaks with $R_{s}<1.5$, there will be some overlap of peak area. Based on the valley between the peak of $\mathbf{1}$ and that one of the earlier eluted compound, a resolution of $R_{\mathrm{s}}=$ 0.98 was estimated for these two adjacent bands. In such cases, the error is always less than $1 \%$ for the larger band
(1) and can be ignored (Snyder et al., 1997). Hence, the chromatographic conditions employed are adequate for quantitative determination of kaurenes $\mathbf{1}$ and $\mathbf{2}$ in aerial parts of $W$. paludosa, expressed as a percentage basis of dry plant mass (Table 4).

Kaurenoic acid (1) was shown to be an abundant diterpene in the aerial parts of $W$. paludosa both in dry (May and August) and rainy (December and January) periods of a year with contents ranging from $0.74 \pm 0.02 \%$ (January, sample 1) to $0.95 \pm 0.04 \%$ (December, sample 4 ), with an average concentration of $0.85 \pm 0.08 \%$ for the dry plant. Previously reported contents of kaurenoic acid (1) are shown in Table 5, along with the results obtained in the present work. The evaluation of the concentration of $\mathbf{1}$ in roots, leaves, stems and flowers of $W$. paludosa in different seasons by HRG/FID has shown a remarkable seasonal variation for plants growing in Florianópolis (southern Brazil). Higher contents were observed in the roots and stems in the autumn $(0.67 \%$ and $0.50 \%$, respectively) while in the winter the concentrations were much lower, especially in the roots $(0.0005 \%)$ (Bresciani et al., 2004). However, for plants growing in Belo Horizonte (south east), the seasonal variation was slight (Table 4) which could be explained by the climatic differences between these regions, particularly during the winter time, with rather lower temperatures in Florianópolis than in Belo Horizonte.

The aerial parts of $W$. paludosa present the highest amount of kaurenoic acid among the species indicated in Table 5, excepting $X$. frutescens seeds. Despite the higher content of $\mathbf{1}$ in $X$. frutescens seeds, W. paludosa should be considered a better source of kaurenoic acid, since it is an easily acessible perennial herb, cultivated with ornamental purposes in different regions of Brazil, whereas $X$. frutescens is a tree found only in the Amazon 
Quantitative determination by HPLC of ent-kaurenoic and grandiflorenic acids in aerial parts of Wedelia paludosa D.C.

Table 4. Content of kaurenoic (1) and grandiflorenic (2) acids in samples of aerial parts of W. paludosa collected during $1998^{\text {a }}$

\begin{tabular}{c|cccc}
\hline Diterpene & $\begin{array}{c}\text { Sample 1 } \\
(\text { Jan. 98) }\end{array}$ & $\begin{array}{c}\text { Sample 2 } \\
\text { (May 98) }\end{array}$ & $\begin{array}{c}\text { Sample 3 } \\
\text { (Aug. 98) }\end{array}$ & $\begin{array}{c}\text { Sample 4 } \\
\text { (Dec. 98) }\end{array}$ \\
\hline 1 & $0.74 \pm 0.02$ & $0.85 \pm 0.02$ & $0.87 \pm 0.03$ & $0.95 \pm 0.04$ \\
2 & $0.31 \pm 0.01$ & $0.32 \pm 0.01$ & $0.30 \pm 0.01$ & $0.33 \pm 0.02$ \\
\hline
\end{tabular}

a Results, expressed as a percentage of dry plant mass, are the mean of triplicates \pm standard deviation.

Table 5. Kaurenoic acid content reported for plant species ${ }^{a}$

\begin{tabular}{|c|c|c|c|c|}
\hline Plant species & Part of the plant & $\begin{array}{c}\text { Kaurenoic acid } \\
\text { content }^{\mathrm{a}}\end{array}$ & $\begin{array}{l}\text { Quantitative } \\
\text { Determination } \\
\text { Method }\end{array}$ & Reference \\
\hline Mikania glomerata & aerial parts & $0.20 \pm 0.01$ & GC & Vilegas et al., 1997 \\
\hline \multirow{4}{*}{ Wedelia paludosa } & flowers ${ }^{b}$ & $0.10^{\mathrm{c}}$ & \multirow{4}{*}{$\mathrm{GC}$} & \multirow{4}{*}{$\begin{array}{l}\text { Bresciani et al., 2000; } \\
\text { Bresciani et al., } 2004\end{array}$} \\
\hline & leaves ${ }^{b}$ & $0.11^{\mathrm{c}}$ & & \\
\hline & stems $^{b}$ & $0.50^{\mathrm{c}}$ & & \\
\hline & roots ${ }^{b}$ & $0.67^{\mathrm{c}}$ & & \\
\hline \multirow{2}{*}{ Annona glabra } & bark & $0.53 \pm 0.02$ & \multirow{2}{*}{ RP-HPLC } & \multirow{2}{*}{ Oliveira et al., 2002} \\
\hline & leaves & $0.27 \pm 0.01$ & & \\
\hline Xylopia aromatica & leaves & $0.02 \pm 0.01$ & RP-HPLC & \multirow{3}{*}{ Melo et al., 2001} \\
\hline Xylopia brasiliensis & leaves & $0.01 \pm 0.00$ & RP-HPLC & \\
\hline Xylopia frutescens & seeds & $3.16 \pm 0.97$ & RP-HPLC & \\
\hline Wedelia paludosa & aerial parts & $0.85 \pm 0.08$ & RP-HPLC & present work \\
\hline
\end{tabular}

${ }^{\text {a }}$ Content expressed as percentage of dry plant mass ( \pm standard deviation).

${ }^{\mathrm{b}}$ Collected in Florianópolis, Brazil, in May 1998.

c Standard deviation not available.

region. Furthermore, overexploitation of $X$. frutescens seeds as source of pharmacologically active compounds may endanger the species.

The amounts of grandiflorenic acid (2) were similar in the four samples of $W$. paludosa assayed and its average concentration was $0.32 \pm 0.02 \%$, almost three times less than kaurenoic acid (1). In the best of our knowledge, this is the first report on the quantitative determination of grandiflorenic acid (2) and the first for both the diterpenoid acids $\mathbf{1}$ and $\mathbf{2}$ in W. paludosa, by HPLC.
In conclusion, our results show that Wedelia paludosa is a valuable source of kaurenoic (1) and grandiflorenic (2) acids.

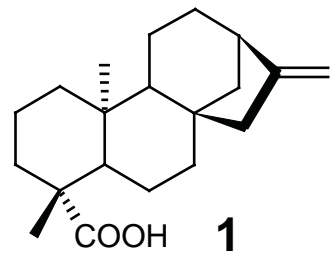

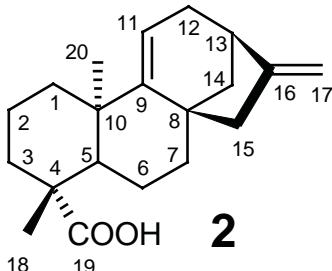

Rev. Bras. Farmacogn. Braz J. Pharmacogn 15(2):abr/jun. 2005 


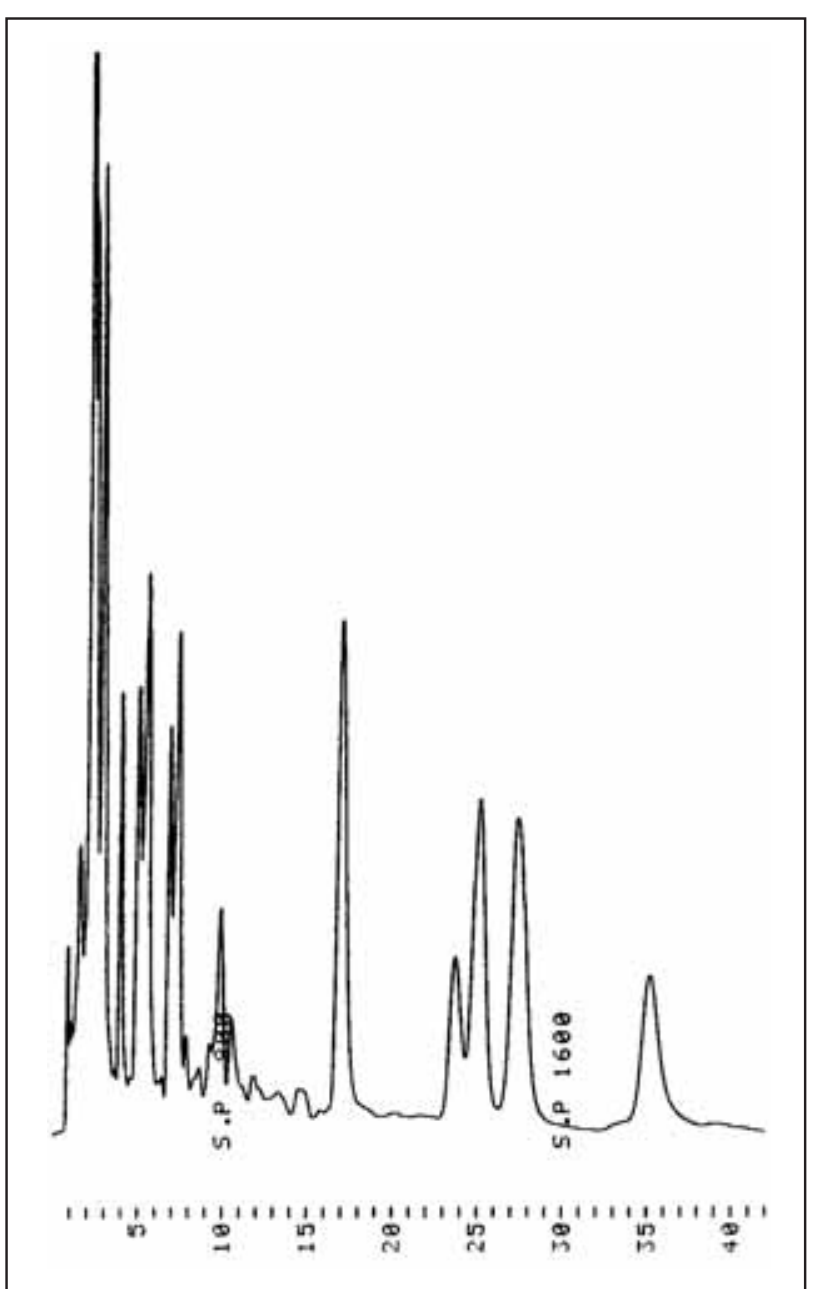

Figure 1. RP-HPLC chromatogram obtained for the analysis of the aerial parts of $W$. paludosa. 1, kaurenoic acid; 2, grandiflorenic acid. Chromatographic conditions: see experimental section.

\section{ACKNOWLEDGEMENTS}

We thank UESB for supporting R. Batista during his Doctorate at The Curso de Pós-Graduação em Ciências Farmacêuticas, Faculdade de Farmácia, UFMG, Belo Horizonte, Brazil, and CNPq for Research Fellowships to $\mathrm{ABO}$ and FCB.

\section{REFERENCES}

Batista R, Chiari E, Oliveira AB 1999. Trypanosomicidal kaurane diterpenes from Wedelia paludosa. Planta Med 65: 283-284.

Block LC, Santos ARS, Souza MM, Scheidt C, Yunes RA, Santos MA, Monache F, Cechinel-Filho V 1998a. Chemical and pharmacological examination of antinociceptive constituents of Wedelia paludosa. $J$ Ethnopharmacol 61: 85-89.

Block LC, Scheidt C, Quintão NLM, Santos ARS, CechinelFilho V 1998b. Phytochemical and pharmacological analysis of different parts of Wedelia paludosa DC
(Compositae). Pharmazie 53: 716-718.

Bresciani LFV, Cechinel-Filho V, Yunes RA 2000. Comparative study of different parts of Wedelia paludosa by gas chromatography. Nat Prod Lett 14: 247-254.

Bresciani LFV, Yunes RA, Burger C, Oliveira LE, Bóf KL, Cechinel-Filho V 2004. Seasonal variation of kaurenoic acid, a hypoglycemic diterpene present in Wedelia paludosa (Acmela brasiliensis) (Asteraceae). Z Naturforsch C 59: 229-232.

Bruno M, Rosselli S, Pibiri I, Piozzi F, Bondi ML, Simmonds MSJ 2001. Semisynthetic derivatives of ent-kauranes and their antifeedant activity. Phytochemistry 58: 463-474.

Carvalho GJA, Carvalho MG, Ferreira DT, Faria TJ, Braz-Filho R 2001. Diterpenos, triterpenos e esteróides das flores de Wedelia paludosa. Quím Nova 24: 24-26.

Chang FR, Yang PY, Lin JY, Lee KH, Wu YC 1998. Bioactive kaurane diterpenoids from Annona glabra. J Nat Prod 61: 437-439.

Chen JH, Xia ZH, Tan RX 2003. High-performance liquid chromatographic analysis of bioactive triterpenes in Perilla frutescens. J Pharm Biomed Anal 32: 11751179.

Chiari E, Duarte DS, Raslan DS, Saúde DA, Perry KSP, Boaventura MAD, Grandi TSM, Stehmann JR, Anjos AMG, Oliveira AB 1996. In vitro screening of Asteraceae species against Trypanosoma cruzi. Phytother Res 10: 636-638.

Cunha KMA, Paiva LA, Santos FA, Gramosa NV, Silveira ER, Rao VS 2003. Smooth muscle relaxant effect of kaurenoic acid, a diterpene from Copaifera langsdorffii on the rat uterus in vitro. Phytother Res 17: 320-324.

Ferreira DT, Levorato AR, Faria TJ, Carvalho MG, Braz-Filho $\mathrm{R}$ 1994. Eudesmanolide lactones from Wedelia paludosa. Nat Prod Lett 4: 1-7.

Ghisalberti EL 1997. The biological activity of naturally occurring kaurane diterpenes. Fitoterapia 68: 303325.

Hanson JR, Hitchcock PB, Takahashi JA1995. Biotransformation of ent-16 $\alpha, 19$-dihydroxykaurane by Cephalosporum aphidicola. Phytochemistry 40: 797-800.

Kubo I, Ganjian I, Kubota T 1982. Chemotaxonomic significance of ent-kaurene diterpenes in Rabdosia umbrosus varieties. Phytochemistry 21: 81-83.

Melo AC, Cota BB, Oliveira AB, Braga FC 2001. HPLC quantitation of kaurane diterpenes in Xylopia species. Fitoterapia 72: 40-45.

Novaes AP, Rossi C, Poffo C, Pretti-Junior E, Oliveira AE, Schlemper V, Niero R, Cechinel-Filho V, Burger C 2001. Preliminary evaluation of the hypoglycemic effect of some Brazilian medicinal plants. Phytother Res 56: 427-430.

Oliveira BH, Sant'Ana AE, Bastos DZL 2002. Determination of the diterpenoid kaurenoic acid in Annona glabra by HPLC. Phytochem Anal 13: 368-371.

Reynolds WF 1984. Total assignment of ${ }^{1} \mathrm{H}$ and ${ }^{13} \mathrm{C}$ spectra of kauradien-9(11),16-oic acid with the aid of heteronuclear correlated 2D spectra optimized for geminal and vicinal ${ }^{13} \mathrm{C}-{ }^{1} \mathrm{H}$ coupling constants: or what to do when "INADEQUATE" is impossible. Can J Chem 62: 2421-2425.

Roque NF, Giannella TL, Giesbrecht AM, Barbosa RCSBC 
1987. Kaurene diterpenes from Wedelia paludosa. Rev Latinoam Quim 18: 110-111.

Sartori MRK, Pretto JB, Cruz AB, Bresciani LFV, Yunes RA, Sortino M, Zacchino SA, Cechinel-Filho V 2003. Antifungal activity of fractions and two pure compounds of flowers from Wedelia paludosa (Acmela brasiliensis) (Asteraceae). Pharmazie 58: 567-569.

Silva EA, Takahashi JA, Boaventura MAD, Oliveira AB 1999. The biotransformation of ent-kaur-16-en-19-oic acid by Rhizopus stolonifer. Phytochemistry 52: 397-400.

Snyder RL, Lirkland JJ, Glajch JL 1997. Practical HPLC method development. 2.ed. New York: John Wiley and Sons, p.714-720.

Vieira HS, Takahashi JA, Boaventura MAD 2000. Biotransformation of methyl ent-17-hydroxy$16 \alpha$-kauran-19-oate by Rhizopus stolonifer. Appl Microbiol Biotechn 53: 601-604.

Vieira HS, Takahashi JA, Oliveira AB, Chiari E, Boaventura MAD 2002. Novel derivatives of kaurenoic acid: preparation and evaluation of their trypanocidal activity. J Braz Chem Soc 13: 151-157.

Vilegas JHY, Marchi E, Lanças FM 1997. Determination of coumarin and kaurenoic acid in Mikania glomerata ("guaco") leaves by capillary gas chromatography. Phytochem Anal 8: 74-77.

Yang YL, Chang FR, Wu CC, Wang WY, Wu YC 2002. New entkaurane diterpenoids with anti-platelet aggregation activity from Annona squamosa. J Nat Prod 65: 1462-1467.

Zgoda-Pols JR, Freyer AJ, Killmer LB, Porter JR 2002. Antimicrobial diterpenes from the stem bark of Mitrephora celebica. Fitoterapia 73: 434-438. 